I. DOSSIÊ: II JORNADA JACQUES DERRIDA 


\title{
TEMPORALIDADE E DIFFÉRANCE: DERRIDA, LEITOR DE FREUD E HUSSERL
}

\author{
Alice Mara Serra \\ Doutora em Filosofia: Universität Freiburg, Alemanha
}

\begin{abstract}
RESUMO
Primeiramente, serão examinados os sentidos em que as teorias de Freud sobre o a posteriori e o traço psíquico contribuem para a formulação de figuras de pensamento centrais da desconstrução: o traço, a arqui-escritura, a différance. Em seguida, será tematizada a crítica de Derrida à filosofia da presença de Husserl. Enfim, será questionado se se trata de manter a polarização estabelecida por Derrida entre o pensamento de Husserl e o pensamento da différance.
\end{abstract}

\author{
PALAVRAS-CHAVE \\ A posteriori, traço, différance, afecção, dom \\ (...) le frayage fracture (...). \\ L’idéalité est le salut ou la maîtrise de la présence \\ dans la répétition. \\ Jacques Derrida
}

Sobretudo em suas primeiras obras, Jacques Derrida ocupa-se de forma intensa com problemas essenciais da fenomenologia de Edmund Husserl: problemas relativos ao signo, ao sentido, à constituição de significados ideais, ao tempo da consciência. Isto se vê, em especial, em Le problème de la genèse dans la philosophie de Husserl (19531954) e em La voix et le phénomène (1967). Paralelamente, dedica Derrida, ao longo de sua obra, fecundas análises sobre a temporalidade a posteriori freudiana, a escrita inconsciente, a resistência do traço, como se vê, por exemplo, em "Freud et la scène de 
l'écriture” (1967), em “Résistances de la psychanalyse” (1991-92), em Mal d'archive: une impression freudienne (1994).

Na leitura de Derrida, os pensamentos de Freud e Husserl aparecem diametralmente correlacionados, respectivamente, como apresentação da différance e ponto culminante da filosofia da presença. Acerca da referência recíproca de Derrida a Freud e a Husserl afirma Hans-Dieter Gondek: "Podemos dizer que Derrida, quando ele lê Husserl, tem Freud em mente e que, inversamente, a referência a Freud não se realiza sem a remissão a Husserl (e a Heidegger).” "1 Também Rudolf Bernet apresenta a tese de que, na leitura de Derrida sobre a fenomenologia de Husserl, Freud atua, segundo o modelo da transferência lacaniana, como uma terceira pessoa, a quem, na verdade, se endereça o discurso. ${ }^{2}$

Derrida afirma que o conceito de tempo formulado por Freud possui um caráter original em relação a toda uma compreensão da temporalidade na tradição metafísica e na fenomenologia:

Que o presente em geral não seja originário, mas reconstituído, que ele não seja a forma absoluta, plenamente vivente e constituinte da experiência, que não haja pureza do presente vivo, este é o tema, formidável para a história da metafísica, que Freud nos chama a pensar através de uma conceptualidade desigual em relação à coisa mesma. $^{3}$

Na visão de Derrida, por sua vez, as teorias de Husserl sobre o tempo e o significado confirmam o domínio do presente vivo e rejeitam o a posteriori (l'après-coup) do tornar-se consciente, ou "a estrutura da temporalidade implicada por todos os textos de Freud". 4

Trata-se, primeiramente, de reconstruir, em linhas gerais, a formulação do conceito de Nachträglichkeit (a posteriori) por Freud, no contexto em que ele aparece (as pesquisas sobre a histeria) e em seus desdobramentos na teoria do traço psíquico. Esse percurso possibilitará situar direções de leitura da Nachträglichkeit e do traço

${ }^{1}$ GONDEK. La séance continue: Jacques Derrida und die Psychoanalyse, p. 197.

2 “(...) Derrida, wenn er sich mit Husserl auseinander setzt, [hat] dabei Freud im Sinn.” (BERNET. Derrida - Husserl - Freud: Die Spur der Übertragung, p. 100.)

${ }^{3}$ DERRIDA. Freud et la scène de l'écriture, p. 314. Essa passagem foi traduzida por mim, assim como todas as demais citadas neste texto, extraídas das respectivas obras em francês (Derrida) e em alemão (Husserl e Freud).

4 DERRIDA. La voix et le phénomène: introduction au problème du signe dans la phénoménologie de Husserl, p. 70 et seq. 
psíquico na obra de Derrida, dentre as quais a elaboração da figura de pensamento da différance e a referência subjacente à fenomenologia de Husserl.

\section{FREUD E DERRIDA: A POSTERIORI E TRAÇO}

Ao ocupar-se, juntamente com Joseph Breuer, nos anos de 1892 a 1895, com a pesquisa sobre a histeria e o atendimento a pacientes histéricas, Freud toma, a princípio, as histórias contadas por estas como narrações de eventos realmente ocorridos. Essa concepção é, contudo, modificada, no contexto em que esses autores vêm a sublinhar o fundamento afetivo-somático das representações psíquicas. Contrariamente à tese de Möbius, Freud e Breuer afirmam que nem sempre as patologias histéricas remetem a representações psíquicas. ${ }^{5}$ Eles apresentam a tese de que a maioria dos fenômenos histéricos tem origem em lembranças não "abreagidas” (abreagierte): 6 são traços de lembranças remissivos a eventos que, no momento em que ocorreram, evocaram um afeto intenso e foram vivenciados sem que tivesse havido uma reação motora correspondente, e sem que tivesse se formado, na consciência, uma respectiva figuração ou uma apreensão predicativa (judicativa) dos mesmos. Uma parte dos estímulos psíquicos associados ao evento teria "retornado" (zurückgelaufen), desenvolvendo-se em sentido contrário ao "tornar-se consciente”, fenômeno que Freud chama de “conversão histérica” (hysterische Konversion). ${ }^{7}$ Quando, num evento subsequente, semelhante àquele primeiro, um afeto análogo é despertado, ou quando o contexto do segundo evento possui traços de semelhança com os traços que, do primeiro evento, tornaram-se conscientes, então ocorre uma associação entre estes dois eventos. Segundo essa concepção da Nachträglichkeit (o a posteriori), o primeiro evento só alcança algum tipo de acesso à consciência a partir de um evento subsequente que a ele se associe por semelhança ou por outro tipo de princípio associativo (como por contraste ou contiguidade).

Essa concepção permite a Freud desenvolver, na clínica, o método da livre associação em substituição às suas primeiras tentativas com a hipnose: não se tratará mais de forçar simplesmente à consciência do paciente a presentificação alucinatória de

5 “(...) hysterisch sind alle diejenigen krankhaften Erscheinungen, die durch Vorstellungen verursacht sind.” (MÖBIUS. Über den Begriff der Hysterie, p. 2.) Ver BREUER; FREUD. Studien über Hysterie, p. 204.

${ }^{6}$ BREUER; FREUD. Studien über Hysterie, p. 210 et seq.

${ }^{7}$ BREUER; FREUD. Studien über Hysterie, p. 188, 201, 224. 
um suposto evento traumático, mas, sim, de possibilitar ao analisando algum tipo de acesso a eventos fundamentais de sua história, mesmo que estes não tenham sido nunca, em sentido estrito, conscientes. A atualização do afeto, que ocorre nesse processo, possibilita menos que um evento anterior se reproduza na consciência "tal e qual ele tenha ocorrido”, e tanto mais que os estímulos psíquicos, outrora retidos aquém da visibilidade consciente ou desviados desta, possam, agora, encontrar outras vias para sua espacialização-temporalização. Como ato psíquico, esta pode se desenvolver seja numa forma mais próxima à lembrança - caso o evento anteriormente recalcado e as vivências que foram atraídas por ele permaneçam como centro da intenção significativo-reprodutiva -, seja sob a forma de imaginação, caso o material psíquico, que outrora não se ligou a palavras ou imagens, possa vir a fazê-lo no presente. Freud constata ser precisamente este meio-termo entre lembrança e fantasia o caráter dos eventos narrados por suas pacientes histéricas: $\mathrm{Na}$ maioria dos casos, havia a dificuldade de classificar as cenas descritas como puras lembranças ou puros atos de fantasia.

Tal fenômeno psíquico, composto de diferentes qualidades - fantasia e lembrança -, investiga Freud também em seu conceito de Deckerinnerung: ${ }^{8}$ esse conceito refere-se não só a lembranças conscientes que encobrem outras lembranças recalcadas, conforme sugere a sua tradução por "lembrança encobridora". 9 Deckerinnerung reconduz principalmente ao verbo alemão "sich decken mit" (“adequar” ou “coincidir com”). Ou seja, diante de certos atos psíquicos, que irrompem na consciência por si mesmos e que apenas parecem ser lembranças, permanece a dúvida do próprio sujeito quanto ao fato de eles "se adequarem ou não a”, ou “coincidirem ou não com” eventos anteriores que tenham sido efetivamente vivenciados. ${ }^{10}$ Partindo de tais constatações, Freud atribuirá cada vez menos valor à ideia de que fenômenos psíquicos, para adquirirem sentido, precisam necessariamente corresponder a alguma realidade física ou experenciada. Em contrapartida, adquire uma importância crescente em sua teoria - assim como nas teorias iniciais de seu mestre de Filosofia em Viena, Franz Brentano, e na visão de Husserl, outro aluno de Brentano - a concepção de "realidade psíquica”, o fato de que conteúdos psíquicos se constituem e

\footnotetext{
${ }^{8}$ Ver FREUD. Über Deckerinnerungen, p. 529-554.

${ }^{9}$ Ver LAPLANCHE; PONTALIS. Vocabulário da Psicanálise, p. 264 et seq.

10 Ver FREUD. Über Deckerinnerungen, p. 546; e SERRA. Zum Phänomen der Deckerinnerung: Eine Auseinandersetzung zwischen Freud und Husserl, p. 23-41.
} 
adquirem sentidos numa rede de interconexão com outros, sem que, para isso, seja necessário recorrer a uma realidade transcendente que os fundamente. ${ }^{11}$

Nesse contexto, a teoria do a posteriori, formulada a princípio no âmbito da histeria, passa a fundamentar também processos psíquicos em que conteúdos se constituem, se associam, se individualizam, afluem à consciência ou se desviam desta, independentemente de serem apropriados pelo eu e de se desenvolverem de modo atencional. Tanto em seu "Projeto de uma Psicologia (científica)" (Entwurf einer Psychologie, 1895), quanto em sua famosa carta a Fliess de $n^{0} .52^{12}$ (1896), Freud apresenta o sistema consciente como uma esfera mais restrita e menos originária que as camadas psíquicas situadas “abaixo” dele, onde tem lugar a sedimentação do traço psíquico (em sentido estrito, inconsciente).

Segundo a abordagem mais dinâmica daquela primeira obra (o Projeto), o traço psíquico proveniente da percepção e de atos de consciência anteriores se dilui, tão logo aparece na consciência, e se sedimenta segundo modos de associação e fragmentação, de temporalização e espacialização, possuindo, na forma do "trilhamento” (Bahnung), princípios de movimento próprios, dentre os quais aceleração, retardamento, adiamento, interrupções. ${ }^{13}$ Os diferentes níveis de intensidade e os jogos de forças envolvidos nesses processos atuam como princípios reguladores dos modos de aparição ou de recusa de passagem de certos estímulos psíquicos a formas de visibilidade consciente. $\mathrm{O}$ que se desenvolve como fenômeno consciente é, nesse sentido, remissão a posteriori a fenômenos associativos, dissociativos, a atos de espacialização e temporalização que ocorrem, por assim dizer, “abaixo” ou "antes” da consciência e independentemente de tomarem a forma de sínteses egoicas. Como o formula Derrida: "Os conceitos de Nachträglichkeit [a posteriori] e de Verspätung [atraso, adiamento], conceitos diretores de todo o pensamento freudiano, são já presentes e chamados pelo nome no Projeto.”14

Como um desdobramento das concepções do Projeto, Freud apresenta, na “Carta

\footnotetext{
${ }^{11}$ Ver, mais detalhadamente, a análise deste tema em SERRA. Archäologie des (Un)bewussten: Freuds frühe Untersuchung der Erinnerungsschichtung und Husserls Phänomenologie des Unbewussten, p. 66 et seq., 71 et seq.

12 Embora conhecida como "Carta 52”, essa carta foi ordenada sob o número 112, na edição não reduzida das cartas de Freud, utilizada neste texto, organizada por J. Masson.

${ }^{13}$ FREUD. Entwurf einer Psychologie, p. 392 et seq.; ver, mais detalhadamente, SERRA. Archäologie des (Un)bewussten: Freuds frühe Untersuchung der Erinnerungsschichtung und Husserls Phänomenologie des Unbewussten, p. 58-145.
}

${ }^{14}$ DERRIDA. Freud et la scène de l'écriture, p. 303. 
52”, os modos de constituição do traço psíquico como uma espécie de escrita que se desenvolve por si mesma, uma escrita não apreensível de forma direta, mas somente modificada, mediata e parcial, segundo aquilo que, a partir de diferentes registros (Niederschriften) e transcrições (Umschriften) inconscientes, se deixa traduzir nas instâncias consciente e pré-consciente. Estas instâncias possuem, a partir disso, o caráter de transcrição de transcrição. ${ }^{15}$ Conforme a leitura de Derrida:

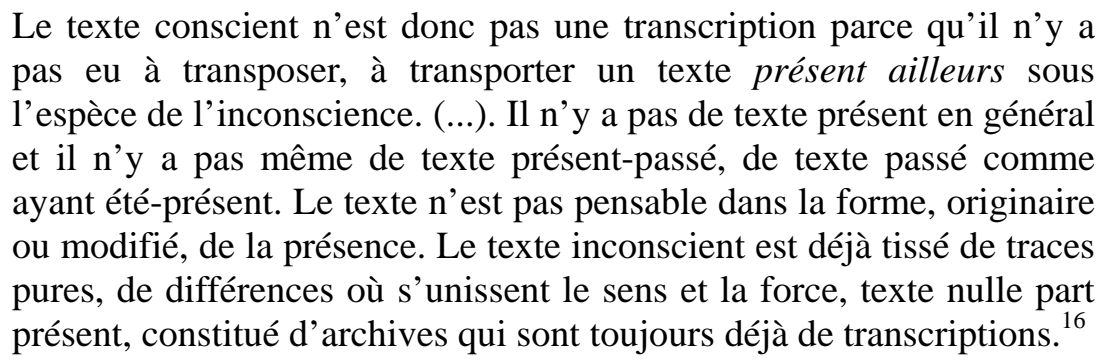

Sob diversos aspectos inerem à concepção freudiana do traço e da escritura psíquica (como Niederschrift e Umschrift) sentidos da figura de pensamento da différance, formulada por Derrida: esta remete, dentre outros significados, aos desvios, adiamentos temporais, espaçamentos e diferenças de forças que subjazem ao tornar-se consciente, à diferenciação entre conteúdos psíquicos e ao esvaecer de sua intensidade e visibilidade. Conforme Derrida, “os dois valores aparentemente diferentes da différance se unem na teoria freudiana: o diferir como discernibilidade, distinção, distância, diastema, espaçamento, e o diferir como desvio, adiamento, reserva, temporalização.”17 O movimento simultâneo de temporalização e espacialização do traço, também denominado de différance (com $a$ ), escapa a uma ideia de tempo contínuo e igualmente não se deixa pensar segundo uma ideia de presença proveniente da percepção, como presença que fosse uma vez apreendida e passível de reapropriação em atos subsequentes. ${ }^{18}$ Em seu diluir-se no momento mesmo em que aparece, em seu fragmentar-se em camadas de sedimentação transcendentes à consciência, camadas plenas de intervalos, interrupções e deslocamentos, a espacialização-temporalização do traço se constitui como hetero-afecção originária, irredutível aos níveis noéticos (atos de julgamento, percepções atencionais, sínteses egoicas). Como escrita em nenhuma parte

\footnotetext{
${ }^{15}$ FREUD. Briefe an Wilhelm Fließ 1887-1904, p. 118 et seq.

${ }^{16}$ DERRIDA. Freud et la scène de l'écriture, p. 313. (grifos do autor)

${ }^{17}$ DERRIDA. La différance, p. 19.

${ }^{18}$ Ver DERRIDA. La différance, p. 1-29.
} 
apreensível, texto somente legível a posteriori, essa esfera, também denominada por Derrida de "arqui-escritura”, remete a processos mais originários que precedem a forma figurativa e a linguagem fonética. Aqui se inverte, como sublinha Derrida, a relação tradicional entre escrita e linguagem fonética da metafísica clássica, segundo a qual a voz viva tem primazia sobre o traço escrito. ${ }^{19}$ Essa esfera de constituição mais originária deve ser pensada como instância não intencional, entendendo-se por intencionalidade, aqui, a definição proposta por Brentano de "ter consciência de algo", ou do "voltar-se intencional a uma objetividade imanente". ${ }^{20}$ Trata-se, todavia, de questionar se e em que medida Husserl conserva essa concepção de intentionalidade de Brentano.

\section{PRESENÇA/E O TRAÇO DE HUSSERL?}

Segundo Derrida, concomitantemente à rejeição do “a posteriori freudiano”, a fenomenologia do tempo de Husserl sublinha a passagem contínua da impressão à retenção, e ainda da percepção à representação, concepções que se embasam numa ideia de presença fundadora de todo e qualquer ato psíquico. ${ }^{21}$ No pensamento de Husserl, a ideia de presença reporta, por um lado, à apreensão unificante dos conteúdos percebidos e sempre passíveis de serem novamente trazidos à consciência, e, por outro, à coincidência visada entre o sentido já constituído e os modos em que ele é apreendido em sínteses ativas, em especial, em atos de linguagem doadores de sentido. A originalidade da abordagem transcendental de Husserl consistiria nesta concepção de idealidade que pode ser infinitamente repetida como "a mesma” em diferentes atos transcendentais, e que, ao mesmo tempo, independe destes para existir. ${ }^{22}$ Tem-se, segundo Derrida, uma identidade "presente a si mesma”, que não se deixa alterar pela linguagem nem se contaminar pelo ser-outro do signo. É nesse sentido que se poderia entender a rígida distinção estabelecida por Husserl, nas Investigações lógicas (Logische Untersuchungen, 1901), entre a esfera dos sentidos ou significados ideais e a esfera dos signos. Derrida acentua que estes possuem um caráter secundário, ao existirem para se referirem ao significado ideal, seja diretamente, como no caso da

\footnotetext{
${ }^{19}$ Ver DERRIDA. De la grammatologie, p. 207 et seq.

${ }^{20}$ BRENTANO. Psychologie vom empirischen Standpunkt, p. 124 et seq.

21 DERRIDA. La voix et le phénomène: introduction au problème du signe dans la phénoménologie de Husserl, p. 5 et seq.

${ }^{22}$ Ver, em especial, em DERRIDA. La voix et le phénomène: introduction au problème du signe dans la phénoménologie de Husserl, o capítulo: "Le vouloir-dire comme soliloque".
} 
modalidade de signo denominada por Husserl de “expressão” ou linguagem significativa (Ausdruck), seja indiretamente, como ocorre nas relações lógicas e associativas da outra modalidade de signo, denominada “indicação" (Anzeigen). ${ }^{23}$

Segundo a crítica de Derrida, Husserl não teria sido capaz de pensar o signo em sua materialidade e dinâmica constitutiva própria, ao reduzi-lo a um mero “transportador de sentido” (Bedeutungsträger), como aparece nas Investigações lógicas. ${ }^{24}$ Derrida tenta salvar, ao menos, a leitura husserliana da indicação, uma vez que Husserl mesmo a havia deixado num lugar secundário, ou melhor, terciário, em relação à expressão e ao sentido: Por exemplo - e este exemplo é de Husserl -, a existência de canais em Marte pode indicar a presença de seres humanos; assim também, o rastro deixado na areia pode indicar a presença de um determinado tipo de cachorro, ou mesmo de um cachorro específico. ${ }^{25} \mathrm{O}$ signo como indicação contém em si, todavia, um horizonte amplo de remissões e significados. E é nesta forma que Derrida também pensa a expressão, recuperando para este campo a impossibilidade de retornar, a partir do signo, a uma intencionalidade ou a uma idealidade mais originárias que tanto o fundariam como o apagariam. Ao pensar o signo como traço, Derrida busca preservar o caráter disseminador do mesmo, em suas múltiplas direções de associação, mas também de dissociação, ruptura e perda. Isso se vê em sua crítica a concepções idealistas ou reducionistas do signo, apagadoras do traço: Ao reduzi-los, seja a uma origem única, seja a uma finalidade específica no interior de uma lógica ou discurso conceitual.

Essa primeira forma de redução do traço (redução a uma origem) pode ser vista, por exemplo, na crítica de Derrida à filosofia da arte de Heidegger; já sua segunda forma de redução ou apagamento (em função de uma presença ideal) teria seu ápice na filosofia transcendental de Husserl. Sublinhe-se que Derrida entende por presença, neste discurso, o significado transcendentalmente constituído, a partir de atos originários de presentificação (Gegenwärtigung), seja esta perceptiva ou intuitiva (como é o caso dos

${ }^{23}$ HUSSERL. Hua XIX/1: Logische Untersuchungen: Untersuchungen zur Phänomenologie und Theorie der Erkenntnis, I, p. 30 et seq. Em DERRIDA. La voix et le phénomène: introduction au problème du signe dans la phénoménologie de Husserl, ver, em especial, o capítulo: "La réduction de l'indice".

${ }^{24}$ HUSSERL. Hua XIX/2: Logische Untersuchungen: Untersuchungen zur Phänomenologie und Theorie der Erkenntnis, VI, p. 546.

${ }^{25}$ HUSSERL. Hua XIX/2: Logische Untersuchungen: Untersuchungen zur Phänomenologie und Theorie der Erkenntnis, I, p. 24. 
números): Idealidade sempre passível de retorno ou repetição em atos de representificação (Vergegenwärtigung) e de linguagem apropriadora, no presente vivo da consciência.

A crítica de Derrida a uma perspectiva idealista refere-se, em especial, à concepção de que um sentido ideal ou um discurso conceitual preexistisse às formas de sua apresentação e se mantivesse em sua identidade consigo mesmo, não se deixando contaminar pelo ser-outro, pelos modos da hetero-afecção em que ele se manifesta. É também uma concepção idealista aquela que desenvolve um diálogo com um outro pensamento, retornando a si como se este diálogo não tivesse ocorrido, como se as marcas do discurso do outro tivessem que sofrer um necessário apagamento para a preservação do mesmo. O discurso da desconstrução, que é, em si, perpassado pelo discurso do outro, e que consiste muito mais em leituras e releituras de textos da tradição e muito menos em um conjunto de teses que lhe sejam “próprias”, deixa-se, ao contrário, alterar pelo traço do outro. ${ }^{26}$ Ora, se assim é, uma leitura não idealista de Derrida é também aquela que não repete as suas teses e posições, mas que, em “iterabilidade” - no sentido dessa repetição que nunca é a mesma -, re-pensa, redimensiona suas figuras de pensamento, re-inaugura seu espaçamento-temporalização em outros territórios.

Nesse sentido, caberia pensar, ainda que brevemente, nesse momento, pontos em que o pensamento de Husserl, ao invés de se manter como idealidade igual a si mesma, como ponto de referência ideal aquém da différance, antes possibilitasse uma reterritorialização de figuras de pensamento da desconstrução.

\section{AFECÇÃO E DOM: PARA UMA ECONOMIA QUASE-GERAL}

Quanto à relação entre percepção e traço de lembrança, consciência do tempo e traço inconsciente, as teorias de Husserl e Freud coincidem em que, no mesmo momento em que percebemos algo do mundo, este algo percebido dilui-se como percepção atual, dando lugar a outras percepções ou outros atos psíquicos. Isto aparece na teoria de Husserl em sua teoria das fases perceptivas, no sentido de que cada momento percebido atualmente traz em si retido ou conservado o momento anteriormente percebido e, por sua vez, retém ou conserva o momento seguinte. ${ }^{27}$ Esta

\footnotetext{
${ }^{26}$ BENNINGTON. Jacques Derrida, p. 12 et seq.

${ }^{27}$ Ver HUSSERL. Hua X: Zur Phänomenologie des inneren Zeitbewusstseins (1893-1917).
} 
estrutura temporal fundamenta, para Husserl, que um ato de percepção passado tenha a possibilidade de se presentificar tal como ele se constituiu: quando um momento temporal de uma fase perceptiva passada torna-se novamente consciente, este momento desperta, por associação, momentos anteriores que, outrora, tomaram parte na mesma fase perceptiva. Isso vale não somente para a percepção e lembrança de objetos temporais, como, por exemplo, um trecho atualmente escutado de uma música que evoque fases anteriores da mesma música. Mas esta estrutura vale também para objetos espaciais, que são igualmente percebidos e rememorados de acordo com fases temporais de apreensão. ${ }^{28}$ Por exemplo, ao observar os objetos dispostos na sala, posso perceber, primeiramente, a mesa; em seguida, a cadeira; à frente, o copo; depois, mais à frente, a janela; por último, a estante. Mas posso também perceber estes objetos “ao mesmo tempo”, devido ao fato de que eles se situam, em relação uns aos outros, de forma contígua, um ao lado de outros. Se, num primeiro momento, eu os percebo de forma contígua, e se, num segundo momento, alguém entra na sala, então, àquela primeira fase de percepção (a percepção dos objetos, quando ainda não havia outra pessoa na sala) sucede uma segunda fase de percepção (a percepção dos objetos na sala e, ao mesmo tempo, da pessoa que entrou). Posteriormente, num ato de lembrança que evoque essa percepção e suas respectivas fases, pode ocorrer, por exemplo, que se torne primeiramente consciente um dos livros que estavam sobre a estante. Por associação segundo a contiguidade, esse livro pode evocar a estante, a mesa ou outros livros que foram percebidos naquele mesmo contexto. Por sua vez, segundo a relação de sucessão, o mesmo livro pode evocar aquela pessoa que entrou na sala e que, supostamente, o tenha apanhado da estante. O referido livro pode ainda chamar à consciência, por semelhança, outros livros anteriormente percebidos, ou ainda, outros livros das mesmas cores e tamanhos, ou outros objetos das mesmas cores. Além disso, pode ocorrer que o livro desperte, por contraste, a representação de algo que eu tenha deixado de fazer quando me dedicara à sua leitura, e assim por diante.

Se, por um lado, os princípios associativos possibilitam que um contexto anterior seja lembrado, por outro, eles, ao mesmo tempo, impossibilitam a repetição pura do respectivo ato de percepção ou de representação intencionado. Essa interferência, no ato de reprodução atual, de outros contextos anteriormente percebidos ou representados

${ }^{28}$ Ver HUSSERL. Hua XVI: Ding und Raum: Vorlesung 1907. 
como reais ou possíveis, atua como fator que dificulta a efetivação da re-presentificação reprodutora.

A pergunta que se coloca é, então, em que medida pode um contexto de percepção ser rememorado tal como ele se constituiu, se em todo ato psíquico há, em cada uma de suas fases e momentos, uma ampla rede de remissões a e de evocação de outros contextos percebidos ou representados. Aqui se incluem também contextos imaginados ou representados como possíveis. Sob a perspectiva de uma filosofia da presença, categoria na qual Derrida inclui o pensamento de Husserl, seria sempre possível trazer novamente à consciência um ato de percepção anterior, na forma em que este tenha se constituído: Parte-se da ideia de que todo conteúdo psíquico (ou noema, segundo a teoria posterior de Husserl), que uma vez tenha se constituído de um determinado modo num determinado ato psíquico, possa ser reconstituído no presente vivo em que ele é novamente intencionado. Nessa estrutura não haveria perda nem desestruturação daquilo que uma vez se individualizou como um “algo" percebido, rememorado, julgado, etc. Essa estrutura seria concomitante àquela, denominada por Derrida de "economia restrita”, que se funda nas ideias de apropriação, reapropriação, captura, troca, escambo entre o sentido dado e as formas em que o discurso o

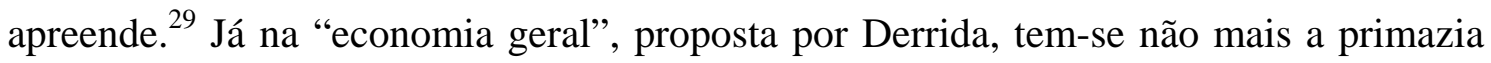
das ideias de domínio, captura e reapropriação do sentido, mas a ideia de soberania. Um sentido que é soberano existe não em função de um discurso ou um saber que dele se aproprie ou reaproprie. Ele é soberano, exatamente por não existir “em função de”, ou “em submissão a” algo outro que ele. O discurso da arte, o discurso da poesia, são, nesse sentido, soberanos, por resistirem a um discurso - teórico, analítico, conceitual que os subjugue ou os encaixe numa constelação conceitual ou hermenêutica (pré)determinada. ${ }^{30}$ Isso também vale para os fenômenos psíquicos: Estes possuem uma dinâmica constitutiva própria, modos de temporalização e espaçamento que precedem a intencionalidade noética e que é soberana em relação a esta. Isso se vê também em Husserl.

Em sua "fenomenologia do inconsciente" tardia, Husserl denomina de “radicalmente pré-egoico” (das radikal Vor-ichliche) esse primeiro e mais originário

\footnotetext{
${ }^{29}$ DERRIDA. De l'économie restreinte à l'économie générale, p. 376 et seq.

${ }^{30}$ Cf. DERRIDA. De l'économie restreinte à l'économie générale, p. 382 et seq.
} 
nível da constituição dos fenômenos psíquicos. ${ }^{31}$ Aí se desenvolvem fenômenos portadores de uma intencionalidade própria, que não se deixa pensar a partir da teoria da intencionalidade formulada por Brentano, no sentido do voltar-se intencional a uma objetividade imanente. Husserl já havia criticado a ideia de imanência da intencionalidade brentaniana e ressaltado a transcendência no interior da imanência transcendental: a distância entre o voltar-se intencional a algo e os diferentes graus de visibilidade em que este algo aparece. Há diferentes níveis de clareza e intensidade: desde representações claras e nítidas, que aparecem quase tão vivazes como percepções reais, passando por representações que aparecem “como em neblina”, até aqueles atos psíquicos, que não chegam a ser atos conscientes, embora pareçam tender a alguma forma de visibilidade. ${ }^{32}$ Este algo, este estímulo intrapsíquico, que ainda não é consciente em sentido estrito, e também não é puramente inconsciente, denomina Husserl de afecção: uma forma anterior à palavra, pré-predicativa e não ainda imagética, mas com algum nível de intensidade, que se apresenta como estágio inicial de todo e qualquer ato psíquico. A afecção pode tanto aceder à figuração ou percepção consciente, como retornar à invisibilidade afectante. Neste movimento de tender à forma de representação consciente e de retornar, no enfraquecer de sua intensidade, possui a afecção uma temporalidade descontínua, um espaçamento próprio: Podendo ser inibida, numa dada fase consciente, ela pode fortalecer-se num momento posterior, despontar na consciência como que "por si mesma”, e despertar, neste processo, o ato de atenção consciente. Este pode tanto recusá-la, ocasionando sua inibição, quando fortalecê-la, fazendo confluírem, neste último caso, a temporalização da afecção e a temporalização egoica. ${ }^{33}$ Husserl distingue propriamente entre esta forma de intencionalidade passiva ou noemática e a intencionalidade ativa ou noética: A primeira refere-se aos atos associativos, dissociativos, às temporalizações-espacializações que ocorrem independentemente dos atos atencionais e demais atos egoicos que lhe voltam $a$ posteriori; a segunda corresponde, em linhas gerais, à intencionalidade em sentido brentaniano, como o "voltar-se para” conteúdos psíquicos. Ao voltar-se a um ato de

${ }^{31}$ HUSSERL. Hua XV: Zur Phänomenologie der Intersubjektivität. Texte aus dem Nachlass. Dritter Teil: 1929-1935, p. 598; ver também: HUSSERL. Materialien VIII (Mat. VIII): Späte Texte über Zeitkonstitution (1929-1934): Die C-Manuskripte.

32 Ver HUSSERL. Hua XI: Analysen zur passiven Synthesis. Aus Vorlesungs - und Forschungsmanuskripten 1918-1926, p. 112 et seq, 148 et seq.

${ }^{33}$ Ver, mais detalhadamente, esta análise em SERRA. Archäologie des (Un)bewussten, p. 198208; 215-224. 
afecção, sempre já em curso, a intencionalidade egoica inicia-se em algum ponto $a$ posteriori em relação à primeira temporalização, de forma que haja não somente um “agora-fonte”, um presente idêntico a si mesmo. Como o formula propriamente Derrida - mesmo que o seja em sua crítica à "identidade do agora consigo mesmo”34 na teoria do tempo de Husserl -, há uma “dobra” (pli) no presente vivo, uma contaminação por dois pontos contíguos do tempo, ao invés de uma retenção contínua de um ponto-agora por outro ponto-agora. ${ }^{35}$

A leitura de Derrida sobre a teoria do tempo de Husserl não é para ser criticada porque ele teria ressaltado apenas, na teoria de Husserl, a coincidência do ponto-agora consigo mesmo (“identité du maintenant comme point”), desconhecendo a estrutura contínua do agora e o horizonte do "campo de presença” (Präsenzfeld), como o querem Ni e Gavota. ${ }^{36}$ Antes, acentua Derrida que a conservação da presença e a possibilidade de sua representificação como “a mesma” fundam-se na estrutura retencional-contínua do ponto-agora. ${ }^{37}$ Todavia, se, conforme os textos tardios de Husserl, há não somente um ponto-fonte da constituição do tempo, mas dois, então, o instante não possui o caráter atribuído por Derrida de coincidência consigo mesmo: O ponto-fonte da temporalização ativa é igualmente um “ponto-entre” e um “ponto-a-posteriori” no curso de uma temporalização-espacialização, cujo início lhe escapa.

A afecção não existe em função de se tornar ato consciente em sentido estrito. $\mathrm{O}$ traço e o signo não existem em função de serem (re)apropriados nas sínteses ativas. Aquém de uma perspectiva arqueológica, que os reconduzisse à sua origem, e além de uma perspectiva teleológica, que os instrumentalizasse do ponto de vista de um saber ou de uma exemplificação de um sistema conceitual dado, resta algo como um traço de exterioridade no interior do mesmo. Em seu modo de "restância” (restance), ${ }^{38}$ que é, em si, inapreensível de forma direta, ele resiste à arqueologia desveladora da origem e à teleologia da (re)apropriação.

\footnotetext{
${ }^{34}$ Tradução não literal de“identité du maintenant comme point”. (DERRIDA. La voix et le phénomène, p. 69).

${ }^{35}$ DERRIDA. La voix et le phénomène, p. 76.

${ }^{36}$ NI. Urbewusstsein und Unbewusstsein in Husserls Zeitverständnis, p. 20 et seq; GAVOTA. Living in the Moment: Husserl, Derrida and the logic of the Now, p. 202 et seq.

${ }^{37}$ DERRIDA. La voix et le phénomène, p. 73 et seq.

${ }^{38}$ Cf. DERRIDA. Résistances de la psychanalyse, p. 40 et seq.
} 
Com isso, não se quer dizer que Husserl tenha pensado a Nachträglichkeit em todas as suas nuances, nem que Husserl tenha radicalizado o caráter de "exterioridade" (dehors) do traço psíquico e do signo. Mas a afecção e seus modos de temporalizaçãoespacialização ajudam a pensar o evento, no sentido derridiano, como algo que aparece sem que estejamos preparados para recebê-lo, uma exterioridade-imanente, índice de não coincidência entre a consciência reveladora ou a palavra apropriadora e a instância indicadora de sentido. ${ }^{39}$

A afecção pode, por si, aparecer ou deixar de aparecer, furtar-se à palavra e à imagem que lhe dão forma a posteriori. Surpreendido pelo que, "por si”, se apresenta, o eu pode não estar preparado para sua recepção. Reafirme-se que esta é, para Derrida, uma das características do dom, ou seja, o fato de que o verdadeiro dom não é nunca um ato intencional e de que nunca estamos prontos para recebê-lo: Não o esperamos, por assim dizer, e é por isso que ele aparece como dom absoluto, como se nos atingisse do alto, à venir - dirá Derrida também a partir de Blanchot -, transgredindo o horizonte da espera. Ao recebermos aquilo que se nos apresenta, ao nos apropriarmos dele, ao transformá-lo em posse, fazemos o percurso inverso, saindo da economia geral e passando à economia restrita. $\mathrm{O}$ fato mesmo de nos tornarmos conscientes da doação faz com que já saiamos da economia geral, passemos à economia restrita.

Nesse sentido, para pensar a relação entre a intencionalidade noemática (o que se doa por si ou que se furta à doação) e a intencionalidade egoica (as modalidades em que nos voltamos a isso ou nos apropriamos disso), vamos lançar mão do conceito de economia quase-geral. Isso nos permitiria pensar a impossibilidade da apropriação e, ao mesmo tempo, a possibilidade de que o sentido - para além das modalidades do $a$ posteriori em que ele se deixa assinalar - possa “restar" (rester) ${ }^{40}$ em si. Ele se manteria, assim, em seu horizonte irrestrito de remissão a outros (outros contíguos, outros passados, futuros, outros contrastantes e semelhantes); horizonte de abertura daquilo que se dá a pensar a partir da interrupção e do corte, que são os modos mesmos de seu trilhamento (Bahnung, frayage) ou fratura (éfraccion) no agora-outro.

\footnotetext{
${ }^{39}$ Cf. DERRIDA. Une certaine possibilité impossible de dire l'événement.

${ }^{40}$ Cf. DERRIDA. Résistances de la psychanalyse, p. 40 et. seq.
} 


\section{RESUMÉ}

Il s’agit d'abord d'examiner la façon dont les théories de Freud sur l'après-coup et la trace psychique contribuent à la formulation de certains concepts fondamentaux de la déconstruction: la trace, l'archiécriture, la différance. Il sera ensuite question de la critique derridienne de la philosophie de la présence de Husserl. Enfin, il faudra se demander dans quelle mesure l’opposition proposée par Derrida entre la pensée de Husserl et la pensée de la différance n'appelle pas un dépassement.

\section{MOTS-CLÉS}

Après-coup, trace, différance, affection, don

\section{REFERÊNCIAS}

BENNINGTON, Geoffrey; DERRIDA, Jacques. Jacques Derrida. Trad. Anamaria. Skinner. Rio de Janeiro: J. Zahar, 1996.

BERNET, Rudolf. Derrida - Husserl - Freud. Die Spur der Übertragung. In: GONDEK, Hans-Dieter; WALDENFELS, Bernhard (Org.). Einsätze des Denkens: Zur Philosophie von Jacques Derrida. Frankfurt: Suhrkamp, 1997. p. 99-123.

BRENTANO, Franz. Psychologie vom empirischen Standpunkt. Hamburg: Felix Meiner, 1973.

BREUER, Joseph; FREUD, Sigmund. Studien über Hysterie. Frankfurt: Fischer, 1996.

DERRIDA, Jacques. Le problème de la genèse dans la philosophie de Husserl (195354). Paris: PUF, 1990.

DERRIDA, Jacques. La voix et le phénomène: introduction au problème du signe dans la phénoménologie de Husserl. Paris: PUF, 1967.

DERRIDA, Jacques (1967). Freud et la scène de l'écriture. In: L'écriture et la différence. Paris: Seuil, 2006. p. 293-340.

DERRIDA, Jacques (1967). De l'économie restreinte à l'économie générale. In: L'écriture et la différence. Paris: Seuil, 2006. p. 369-407.

DERRIDA, Jacques. De la grammatologie. Paris: Minuit, 1967.

DERRIDA, Jacques. La différance. In: . Marges de la philosophie. Paris: Minuit, 1972. p. 1-30.

DERRIDA, Jacques (1995). Mal d'archive: une impression freudienne. 2. ed. Paris: Galilée, 2008. 
DERRIDA, Jacques. Résistances de la psychanalyse. Paris: Galilée, 1996.

DERRIDA, Jacques (1997). Une certaine possibilité impossible de dire l'événement. In: Dire l'événement, est-ce possible? Paris: L’Harmattan, 2001. p. 81-112.

FREUD, Sigmund (1895). Entwurf einer Psychologie GW Nachtragsband: texte aus den Jahren 1885-1938. Frankfurt: Fischer, 1987. p. 373-486.

FREUD, Sigmund. Briefe an Wilhelm Fließ 1887-1904. Ed. J. M. Masson. Frankfurt: Fischer, 1986.

FREUD, Sigmund. Über Deckerinnerungen (1899). GW I: Werke aus den Jahren 18921899. 5. ed. Frankfurt: Fischer, 1977. p. 529-554.

GAVOTA, Gina. Living in the Moment: Husserl, Derrida and the logic of the Now. In: BANHAM, Gary (Org.). Husserl and the logic of Experience. Basingstoke: Palgrave Macmillan, 2005. p. 202-216.

GONDEK, Hans-Dieter. La séance continue: Jacques Derrida und die Psychoanalyse. In: DERRIDA, Jacques. Vergessen wir nicht: die Psychoanalyse!. Ed. e trad. H.-D. Gondek. Frankfurt: Suhrkamp, 1980. p. 179-232.

HUSSERL, Edmund. Hua X: Zur Phänomenologie des inneren Zeitbewusstseins (18931917). Ed. R. Boehm. Haag: Nijhoff, 1966.

HUSSERL, Edmund. Hua XI: Analysen zur passiven Synthesis. Aus Vorlesungs - und Forschungsmanuskripten 1918-1926. Ed. M. Fleischer. Den Haag: Martinus Nijhoff, 1966.

HUSSERL, Edmund. Hua XV: Zur Phänomenologie der Intersubjektivität. Texte aus dem Nachlass. Dritter Teil: 1929-1935. Ed. I. Kern. Den Haag: Martinus Nijhoff, 1973.

HUSSERL, Edmund. Hua XVI: Ding und Raum: Vorlesung 1907. Ed. U. Claesges. Den Haag: Nijhoff, 1973.

HUSSERL, Edmund. Hua XIX/1: Logische Untersuchungen: Untersuchungen zur Phänomenologie und Theorie der Erkenntnis. Hrsg. von U. Panzer. The Hague: Martinus Nijhoff, 1984.

HUSSERL, Edmund. Hua XIX/2: Logische Untersuchungen: Untersuchungen zur Phänomenologie und Theorie der Erkenntnis. Ed. U. Panzer. The Hague: Martinus Nijhoff, 1984.

HUSSERL, Edmund. Materialien VIII (Mat. VIII): Späte Texte über Zeitkonstitution (1929-1934): Die C-Manuskripte. Ed. D. Lohmar. Dordrecht: Springer, 2006.

LAPLANCHE, Jean; PONTALIS, Jean-Bertrand. Vocabulário da Psicanálise. 2. ed. Trad. Pedro Tamen. São Paulo: Martins Fontes, 2004.

MÖBIUS, Paul J. Über den Begriff der Hysterie. In: __. Neurologische Beiträge, Bd. I: Über den Begriff der Hysterie und andere Vorwürfe vorwiegend psychologischer Art. Leipzig: Abel, 1894. p. 1-7.

NI, Liangkang. Unbewusstsein und Urbewusstsein in Husserls Zeitverständnis. Husserl Studies 21, p. 17-33, 2005.

SERRA, Alice M. Zum Phänomen der Deckerinnerung: Eine Auseinandersetzung zwischen Freud und Husserl. Phänomenologische Forschungen. Hamburg, p. 23-41, 2008. 
SERRA, Alice M. Archäologie des (Un)bewussten: Freuds frühe Untersuchung der Erinnerungsschichtung und Husserls Phänomenologie des Unbewussten. Würburg: Ergon, 2010. 